EGU21-15591, updated on 04 May 2021

https://doi.org/10.5194/egusphere-egu21-15591

EGU General Assembly 2021

(c) Author(s) 2021. This work is distributed under

the Creative Commons Attribution 4.0 License.

\title{
Downward particle flux in the open ocean: Future global opportunities and insights from time-series measurements at the PAP Sustained Observatory in the Northeast Atlantic.
}

\author{
Richard Lampitt \\ National Oceanography Centre, Ocean BioGeosciences, Southampton, United Kingdom (r.lampitt@noc.ac.uk)
}

The Joint Global Ocean Flux Study (JGOFS) started in 1987 and stimulated massive integration of efforts to measure and understand the processes of downward flux in the ocean. A small number of sustained observatories have persisted from this time in the belief that a key to gaining this understanding is by prolonged time-series observations. The sustained observatory over the Porcupine Abyssal Plain (PAP-SO) in the Northeast Atlantic is one such site which has provided nearly continuous measurements of downward flux at a depth of $3000 \mathrm{~m}$ since 1989 . This was using sediment traps but, in order to understand the data, we have exploited a wide range of other approaches such as optical methods, drifting sediment traps in the upper $1000 \mathrm{~m}$, chemical variables near the surface and computational modelling. Insights are also gained from the Continuous Plankton Recorder (CPR), satellite observations and various climatic indices.

This presentation draws together these measurements to quantify and understand flux at $3000 \mathrm{~m}$. Seasonal and interannual variability is large but after 30 years of observation, explanations are now possible. In addition, some of the conclusions identify major and surprising features about the ways ecosystems in one year may be influenced by their structure and function in previous years.

At the same time as these time-series observations have been in progress, major new developments have taken place globally and at PAP-SO to provide additional and alternative means to asses flux. The sediment trap has significant advantages as well as uncertainties which have been described previously. The new era of approaches using, for instance, BGC Argo, the Carbon Flux Explorer and a variety of other optical techniques offer what may be a quantum leap in our understanding of downward particle flux now and how it is changing in response to changes in the global climate. This presentation will give a personal and optimistic view of the opportunities which are now developing to quantify and understand this crucially important process. 